\title{
Empty Nest- Mirrored in a growing mind: A Case Report
}

\author{
Shakya DR \\ Associate Professor, Department of Psychiatry, BPKIHS, Dharan, Nepal \\ E mail Corresponding Author: drdhanashakya@yahoo.com
}

\begin{abstract}
We report a case of 'depression' with 'empty nest syndrome' to highlight the importance of parents for psychic development and of family support for effective management of psychiatric disorder.

A 21-year-old lady presented with history of feeling lonely for 2-years, sadness 1 year; and insomnia and death wishes 3 months. She was staying in her home-town with uncle as both parents went abroad 8 years back. She started missing her parents when she had frequent pain abdomen in last 3 years, she could not succeed in examination and friends were away from her. As her uncle and aunt were also busy preparing for abroad work, she increasingly felt lonely and empty in last 2 years.

With growing loneliness, she felt sad and worried. She reported losing interest, feeling weaker and having ruminating thoughts in last year. In between, she met a boy-friend whom she found supportive; but soon, she started worrying that her parents might not agree to this relationship. In distress, she slashed her wrists. Because of her condition, her parents started visa process, which eased for some time. Despite of visa progress, she could not sleep due to worrying thoughts. She expressed suicidal thoughts many times. And, her relatives brought her for psychiatry consultation, though reluctantly. With diagnosis of 'depressive episode', she was put on supervised Mirtazapine and Lorazepam. She was also provided psychotherapy which focused on coping and problem solving strategies addressing her 'empty nest syndrome', and family members were advised 'suicide-precaution'.
\end{abstract}

Key words: Depression, empty nest syndrome, Nepal, psychiatric co-morbidity.

\section{INTRODUCTION}

'Empty nest syndrome' is a persistent and pervasive feeling of loneliness, sadness, and or grief that parents and or other guardian relatives may undergo when their children leave home. ${ }^{1-2}$ Many productive couples go abroad in search of better opportunities leaving their children in home. Current day Nepal is witnessing such issues more than any other sections of its history. ${ }^{3}$

Lack of parents during growing up could impact child's growth and development. ${ }^{4}$ Finding their 'nest', i.e. home 'empty', i.e. devoid of parents, the growing child might endure a range of feelings from loss and sadness to relief and freedom, and might resort to unhealthy coping, e.g. premature relationship and substance use. ${ }^{4-5}$ Vicious cycles of loneliness and unhealthy coping might result in ill health, both physical and mental. ${ }^{2}$ Here is a case of 'empty nest syndrome' that turned into 'clinical depression' with suicidal risk. This case is expected to highlight the significance of family support for the maturation of ego and for effective management of psychiatric problem.

\section{CASE REPORT}

A 21-year-old lady was brought for psychiatry consultation in a teaching hospital in eastern Nepal, B. P. Koirala Institute of Health Sciences by her relative with history of feeling lonely for 2-years; increasing sadness for 1 year and insomnia and suicidal thoughts for 3 months.

She had been staying in Kathmandu, her home town with her uncle although both of her parents went to United States of America 8 years ago. Absence of both parents was stressful for her which got worst when others commented and remarked about her parents' leaving her alone in uncles' home. With increasing age, she finished her SLC with good grades, completed certificate level and had joined bachelor level.

She started having frequent pain abdomen in last 3 years. The pain was at times severe and associated with nausea, vomiting and water brash. Her menstrual cycles were also irregular. She had 
multiple medical consultations for the diagnosis and treatment of the problem. She was investigated and treated many times in the line of acid peptic disease, and having possible ovarian cyst which was deferred later. Despite multiple consultations, she continued to have pain abdomen. She felt neglected by her uncle and aunt, and started missing her parents. She could not focus on her study as before and she failed in her examinations. Her class mates and friends went away on their own business and she started increasingly feeling lonely, empty and sad for last 2 years.

During this period, she got in relationship with a boy whom she found to be supportive. Soon, she started worrying about their relationship as she knew that her father would not approve of such relationship. She got more distressed and started self mutilating mainly slashing her wrists many times. She reported feeling more depressed and losing interest in her daily routines. Because of her condition, her parents started visa process to call her to the USA. This eased her distress for some time but did not last long. She continued to feel depressed, have suicidal thoughts and had lost significant amount of weight. Despite of the prior psychiatry referral by treating doctors, they did not consider the need before and only then; she was brought to psychiatric service.

She wept while talking about her parents. Though visa process was progressing, she continued to feel hopeless and had suicidal thoughts without intent. There was no history of fever, loss of consciousness, seizure, delusions, hallucinations and disorientation. There was no significant family psychiatric illness. She denied using any psychoactive substance. The accompanying relative informed prior to this episode she used to be well adjusted.

All the medical investigations (stool for occult blood, blood sugar, electrolytes, creatinine, ultrasound-abdomen, blood counts and thyroid function tests) were within normal range.

With the diagnosis of 'depressive episode', she was put on Mirtazapine and Lorazepam. Family members were advised about suicide precaution. She was also provided psychotherapy which focused on coping and problem solving strategies, along with psychological interventions addressing her 'empty nest syndrome'. Then her parents arrived and soon she left Nepal with them. And, she did not come for follow up.

\section{DISCUSSION}

'Empty nest syndrome' is basically described among the parents and other guardian relatives whose children leave them in home. Similar state may be seen in other family members, including children. This condition of persistent sadness and loneliness is increasingly seen in countries like Nepal where people are moving across for various reasons. ${ }^{2,3}$ Presently, Nepal is witnessing an unprecedented movement of people in search of better education and employment. ${ }^{6-7}$ This has impacted not only the health of foreign job holders ${ }^{8}$ but also their family members; especially the spouses were reported to be affected. ${ }^{4}$ The psychological health of children who are left behind is discussed in this case-report.

In quest of modern life and progress, priority might shift from family to work and study. For a growing child however; parents are the best model, the caregiver and the guide. An offspring consolidates its ego with the support of unconditionally responsible and available parents. When parents are not available at this crucial period, growth and development of a growing child or adolescent might be affected.

Many children are left in home or hostels away from their parents who are working out of home or abroad. Due to lack of emotional support, guidance and model; many of these children have problem in adjustment, emotion and behavior. They are vulnerable to substance ab/use, premature relationship or other harmful/ unhealthy habits. ${ }^{4}$ An attempt has been made to draw attention towards this situation through this case-report. Due to lack of adequate preparation and support, many such children may be in similar situation. This seriously warrants a systematic study.

Accordingly, family members and the moving members need to adequately prepare for wellbeing of their children prior to making such moves. 
Adequate education and information (of possible consequences, available services and resources, stress management and coping skills); support network; hostels with emotional support, conducive environment and effective monitoring; child friendly policies and health service and security for these children through a proper mechanism are some of the strategies that might help mitigate such problems of these children and their parents.

Mental illness i.e. emotional and behavioral problems might affect these children and adolescents, even more. Many Nepalese people still harbor stigma and myths about mental illness and its treatment. ${ }^{9}$ In this case; family members took almost 2 years to seek help from psychiatric service despite of psychiatric referrals. Family members need to be aware of the risk of mental illness and should not hesitate to seek help. We need to break ice of stigma with better awareness program.

\section{REFERENCES}

1. Psychology Today's Diagnosis Dictionary: Empty nest syndrome.

http://www.psychologytoday.com/conditions/emptynest.ht $m l$.
2. Shakya DR. Empty nest syndrome- an Obstacle for alcohol abstinence: a case report. Journal of Nepal Health Research Council (JNHRC). 2009 Oct; 7(2):135-137.

3. Shakya DR. Culture change and mental health. In: Souvenir of national CME of Psychiatrists' Association of Nepal', 2007. Page 12-15.

4. Thamas B, Adhikari S. Male migration: Dynamics, Issues and Difficulties of left behind families. Asia Pacific Journal of Social Sciences. 2012 Jan-Jun; 4(1):109-130.

5. Fahrenberg B. Coping with the empty nest situation as a developmental task for the aging female-an analysis of the literature. Z Gerontol. 1986 Sep-Oct;19(5):323-35. Accessed online November 2011. (Abstract)

6. World Federation for Mental Health. World Mental Health Day 2007. www.wfmh.org. Accessed online December 2007. 24.

7. Shyangwa PM, Lamichhane N, Shakya R, Shakya DR, Sapkota N. Psychiatric morbidity in foreign job holders. J Gandaki Medical College. June 2009; 2(2):45-52.

8. Shakya DR. Psychiatric Morbidity Profiles of female Spouses of Nepalese abroad workers. Program and Abstract Book of 10 $10^{\text {th }}$ World Congress of World Association for Psychosocial Rehabilitation. Bangalore, India 2010 November. Pp. 158.

9. Shakya DR. Psychiatric emergencies in Nepal. Developing Mental Health, International Journal for Mental health care. UK. 2008; 6(8): 5-7. 